\title{
The Prevalence of Gout and Its Risk Factors in Healthy Workers
}

\author{
Gi-Hong Kwon'1, Byung Yeol, Chun², Yong Hyun, Kwon \\ 'Division of Health and Science, Yeungnam University College, Daegu; ${ }^{2}$ Department of Preventive Medicine and Public Health, School of Medicine, \\ Kyungpook National University; ${ }^{3}$ Department of Physical Therapy, Yeungnam University College, Daegu, Korea
}

Purpose: This study was conducted to investigate the prevalence and risk of gout in healthy workers.

Methods: This cross-sectional analysis was conducted in 1,876 subjects (1,515 men and 361 women) enrolled in the Healthy Worker Cohort Study at Daegu, South Korea. Relationships between serum uric acid levels and independent risk factors were evaluated using multiple linear regression analysis after adjustment for covariates.

Results: Among study participants, the prevalence of gout was 22.9\% in men and 2.5\% in women (based on a serum uric acid level $>7.0 \mathrm{mg} / \mathrm{dL}$ for men and $>6.0 \mathrm{mg} / \mathrm{dL}$ for women). Among men, increased ALT, GGT, total cholesterol, and triglycerides were associated with increased risk of gout $(p<0.05)$ by multiple linear regression analysis; however, increased age and HDL-cholesterol/triglyceride ratio were associated with decreased risk of gout $(p<0.05)$. In women, increased triglycerides were associated with increased risk of gout $(\mathrm{p}<0.05)$.

Conclusion: Our findings suggest that increased triglycerides were significantly associated with the risk of gout in men and women. Moreover, a high $\mathrm{HDL}$-cholesterol/triglyceride ratio in men may reduce the risk of gout.

Keywords: Gout, Risk factor, Blood lipids

\section{서 론}

통풍은 혈액 중 요산이 증가되는 질병으로 관절염, 신장기능저하, 뇨 결석 등을 초래하고 통증이 심한 경우에는 보행 장애까지 동반한다. 통풍은 현재 유병률이 계속 증가하고 있는 실정으로 고요산혈증에 대한 예방과 치료에 대한 관심이 증가하고 있으며, 대사증후군이나 심혈관계 질환과의 연관성에 대해서 많이 밝혀지고 있다.2-5 통풍과 심장질환과의 코호트 연구에서 관상동맥질환 환자에서 통풍이 $60 \%$ 가 더 많이 발생하였고, ${ }^{6} \mathrm{Chen}$ 등은 통풍의 발작 빈도가 심근경색의 발생과 관련이 있다고 보고되었다. Full 등의 연구에서는 통풍 환자 에서 급성 심근경색의 위험률이 $26 \%$ 정도 증가한다고 하였고, 건강전 문기관의 추적검사결과에서는 통풍 환자에서 심혈관 질환으로 인한 사망률의 상대위험도가 높다고 하였다.9.10 이와 같은 심혈관계 질환 과의 연관성은 고요산혈증으로 인한 혈관 내피세포의 기능 저하를 초래하는 염증 반응이 심혈관 질환의 발생에 주요한 기전으로 제시 되었으나, 통풍과 심혈관 질환과의 직접적인 연관성에 대해서는 아직 도 명확히 알려져 있지 않다.111,

통풍은 고요산혈증과 대사증후군, 즉 고인슐린혈증, 고혈압, 고지

Received Sep 12, 2016 Revised Oct 23, 2016

Accepted Oct 31, 2016

Corresponding author Yong Hyun, Kwon

E-mail kwonpt@daum.net
혈증, 비만 등과 밀접한 연관성이 있다고 밝혀지고 있으며, ${ }^{13}$ 미국의 국립 건강 영양 검진결과에서는 통풍 환자가 대사 증후군의 유병률 이 건강인보다 더 높았다고 보고하였다. ${ }^{14}$ 통풍 환자에서 대사 증후 군이 증가하는 기전으로는 고요산혈증이 있는 환자를 치료한 결과 에서 혈관 내피 세포의 기능이 향상되었고, 이는 고요산혈증이 혈관 내피세포의 대사증후군에 기능 이상을 초래한다는 것이다. ${ }^{15}$ 또한 요 산에 의해 지방 세포가 염증 변화 및 산화되어 발생된다는 기전도 함 께 제시되고 있다. ${ }^{16}$ 요산은 체내의 대사나 외부에서 생성된 purine의 대사산물이 과도하게 축적된 현상인데 주로 육류와 과당이 많이 함 유된 음료와 술의 과다한 섭취로 인해 발생한다고 알려져 있으며, 17,18 혈청 호모시스텐 수치나 혈청 지질과도 관련이 있다. ${ }^{19}$

통풍은 류마티즈 관절염, 강직성 척추염, 건선 관절염 등과 같이 대 표적인 염증성 관절 질환 중의 하나로, 발을 포함한 하지에 통증을 유 발하고 감소된 운동성, 관절 기형, 기능적 장애, 비정상적인 보행을 유 발한다.1,6-10 통풍이 과도한 요산 대사의 문제로 인해 관절과 연부 조 직 내에 요산일 나트륨 결정체(monosodium urate crystals)가 축적되 어 문제를 발생하기 때문에 혈중 요산의 농도를 정상화시키는 것이 가장 주된 치료이다. 특히 통풍은 요산의 증가로 인해 관절 내 또는
Copylight (C2016 The Korea Society of Physical Therapy

This is an Open Access article distribute under the terms of the Creative Commons Attribution Non-commercial License (Http:// creativecommons.org/license/by-nc/4.o.) which permits unrestricted non-commercial use, distribution, and reproduction in any medium, provided the original work is properly cited. 
주변 병변에서 발생하는 통증, 부종, 관절 가동성 제한, 보행 장애를 유발하기 때문에 근골격계 기능 개선을 위한 적극적인 물리치료가 필요한 실정이다. 그러나 통풍 치료에 대한 물리치료는 임상에서 매 우 다양한 방법으로 치료되고 있지만, 아직 통풍에 대한 관심도는 현 실적으로 높지 않고 물리치료의 치료 지침에 대한 문헌은 부족하다. 따라서 본 연구에서는 지역사회의 일부 근로자들을 대상으로 통풍 의 발생 빈도를 조사하고, 생활 습관과 혈청지질 및 간기능 지표들과 통풍과의 관련성을 조사하였다.

\section{연구 방법}

\section{1. 연구대상}

연구 대상자들은 대구광역시 일부 지역의 근로자들로서 연구 참여 에 동의한 사람들 4,346 명 중 1 년 후 혈액학적 검사, 설문조사, 그리고 피험자 동의서를 완성한 20-69세 사이의 건강한 근로자 1,876명이(남 자 1,515 명, 여자 361 명) 임의로 추출되어 최종 분석대상자에 포함되 었다. 이 연구는 계명대학교 의과대학의 연구윤리위원회의(institutional review boards) 동의를 받은 후에 수행되었다.

\section{2. 실험방법}

1) 혈청학적 검사

연구대상자의 공복 혈청을 $10 \mathrm{~mL}$ 채취하여 aspartate aminotransferase (AST), alanine aminotransferase (ALT), gamma-glutamyl transpeptidase (GGT), HDL-cholesterol (HDL), Total cholesterol (Total C), triglyceride, 그리고 glucose를 측정하였다. 분석은 ADVIA1800 Auto Analyzer (Simens Medical Solutions USA, Inc., Malvern, PA, USA)을 이용하였다.

\section{2) 설문조사}

설문지는 미리 고안된 일반건강검진 설문지를 이용하였고, 연구 대상 자의 연령, 흡연력, 음주력, 운동습관에 대해 자기 기입식으로 응답하 게 하였다. 흡연력은 비흡연과 현재흡연으로, 음주력은 비음주와 현 재음주로 구분하였다. 운동습관의 설문조사에서, 심한 운동(vigorous exercise)은 달리기, 에어로빅, 빠른 속도로 자전거 타기, 등산 등의 운동을 평상시 활동보다 숨이 횔씬 더 가쁘게 만드는 격렬한 활동을 하루 약 20 분 이상 하였을 때, 중증도 운동(moderate exercise)은 빠르 게 걷기, 복식 테니스치기, 보통 속도로 자전거 타기 등의 운동을 평상 시 활동보다 숨이 조금 더 가쁘게 만드는 중간 정도의 활동을 하루 약 30 분 이상 하였을 때, 경증도 운동(mild exercise)은 가벼운 운동이 나 출퇴근 또는 여가시간 걷기 등을 하루 30 분 이상 하였을 때로 세 분화하여 '예, '아니오' 로 응답하게 하였다.

\section{3. 통계학적 분석}

범주형 자료는 도수와 비율로 표시하였다. 고요산혈증의 정의는 남 자는 혈중요산 농도가 $7.0 \mathrm{mg} / \mathrm{dL}$ 을 초과할 때, 여자는 $6.0 \mathrm{mg} / \mathrm{dL}$ 을 초 과할 때로 정의하였다. ${ }^{20}$ 단순분석에서 범주형 자료의 분석은 카이제 곱 검정법을 이용하였고, 연속자료의 관련성 평가는 상관분석기법 (correlation analysis)을 이용하였다. 그리고 다변량 분석은 요산수치를 종속변수로 한 다중 선형회귀분석 기법(multiple linear regression analysis)을 이용하여 분석하였다. 유의수준은 0.05 미만으로 규정하 였고, 모든 통계분석은 IBM SPSS Statistics 19.0 (IBM Corp., Armonk, NY, USA)을 사용하였다.

\section{결 과}

\section{1. 유병률}

2014년 기준 연구대상자들의 고요산혈증 유병률은 남자 1,515 명 중

Table 1. The prevalence of gout by gender

\begin{tabular}{lccc}
\hline Gender & No. of subject & No. of hyperuricemia* & Prevalence (\%) \\
\hline Men & 1,515 & 347 & 22.9 \\
Women & 361 & 9 & 2.5 \\
\hline
\end{tabular}

"gout (men $7[\mathrm{mg} / \mathrm{dL}]<$, women $6[\mathrm{mg} / \mathrm{dL}]<$ )

Table 2. Frequency distribution of study subjects by gender

\begin{tabular}{lccccc}
\hline \multirow{2}{*}{ Independent variable } & \multicolumn{2}{c}{ Men $(\mathrm{N}=1,515)$} & & \multicolumn{2}{c}{ Women $(\mathrm{N}=361)$} \\
\cline { 2 - 3 } \cline { 5 - 6 } Age (year) & No. of subject & $\%$ & & No. of subject & $\%$ \\
$20-29$ & 182 & 12.0 & 42 & 11.6 \\
$30-39$ & 476 & 31.4 & 68 & 18.8 \\
$40-49$ & 440 & 29.0 & & 185 & 51.2 \\
$50-59$ & 356 & 23.5 & & 62 & 17.2 \\
$60-69$ & 61 & 4.0 & & 4 & 1.1 \\
Smoking & & & & \\
No & 742 & 49.0 & 339 & 93.9 \\
Yes & 773 & 51.0 & & 22 & 6.1 \\
Alcohol drinking & & & & \\
No & 402 & 26.5 & & 215 & 59.6 \\
Yes & 1,113 & 73.5 & & 146 & 40.4 \\
Vigorous exercise & & & & \\
No & 1,285 & 84.8 & 320 & 88.6 \\
Yes & 230 & 15.2 & 41 & 11.4 \\
Moderate exercise & & & & & \\
No & 1,274 & 84.1 & 298 & 82.5 \\
Yes & 241 & 15.9 & 63 & 17.5 \\
Mild exercise & & & & \\
No & 996 & 65.7 & 226 & 62.6 \\
Yes & 519 & 34.3 & 135 & 37.4 \\
\hline
\end{tabular}


347 명으로 $22.9 \%$ 를 차지하였고, 여자는 361 명 중 9명으로 $2.5 \%$ 를 차 지하여 남자에 비해 여자에게서 유병률이 훨씬 낮았다(Table 1).

\section{2. 인구학적인 데이터 분석}

연구대상자 수는 전체 1,876 명 중 남자 1,515 명, 여자 361 명으로 남자가

Table 3. The prevalence of gout by independent variable and gender

\begin{tabular}{|c|c|c|c|c|}
\hline \multirow[b]{2}{*}{$\begin{array}{l}\text { Independent } \\
\text { variable }\end{array}$} & \multicolumn{2}{|c|}{ Men } & \multicolumn{2}{|c|}{ Women } \\
\hline & $\begin{array}{c}\text { No. of } \\
\text { hyperuricemia } \\
\text { /No. of } \\
\text { subject }\end{array}$ & $\begin{array}{c}\text { Prevalence } \\
\text { (\%) }\end{array}$ & $\begin{array}{c}\text { No. of } \\
\text { hyperuricemia } \\
\text { /No. of } \\
\text { subject }\end{array}$ & $\begin{array}{c}\text { Prevalence } \\
(\%)\end{array}$ \\
\hline \multicolumn{5}{|l|}{ Age (year)* } \\
\hline $20-29$ & $56 / 182$ & 30.8 & $2 / 42$ & 4.8 \\
\hline $30-39$ & $115 / 476$ & 24.2 & $1 / 68$ & 1.5 \\
\hline $40-49$ & $99 / 440$ & 22.5 & $4 / 185$ & 2.2 \\
\hline $50-59$ & $69 / 356$ & 19.4 & $2 / 62$ & 3.2 \\
\hline $60-69$ & $8 / 61$ & 13.1 & $0 / 4$ & 0.0 \\
\hline \multicolumn{5}{|l|}{ Smoking } \\
\hline No & $184 / 742$ & 24.8 & 9/339 & 2.7 \\
\hline Yes & $163 / 773$ & 21.1 & $0 / 22$ & 0.0 \\
\hline \multicolumn{5}{|c|}{ Alcohol drinking } \\
\hline No & $82 / 402$ & 20.4 & $6 / 215$ & 2.8 \\
\hline Yes & $265 / 1,113$ & 23.8 & $3 / 146$ & 2.1 \\
\hline \multicolumn{5}{|c|}{ Vigorous exercise } \\
\hline No & $286 / 1,285$ & 22.3 & $7 / 320$ & 2.2 \\
\hline Yes & $61 / 230$ & 26.5 & $2 / 41$ & 4.9 \\
\hline \multicolumn{5}{|c|}{ Moderate exercise } \\
\hline No & $290 / 1,274$ & 22.8 & $7 / 298$ & 2.3 \\
\hline Yes & $57 / 241$ & 23.7 & $2 / 63$ & 3.2 \\
\hline \multicolumn{5}{|l|}{ Mild exercise } \\
\hline No & 221/996 & 22.2 & $4 / 226$ & 1.8 \\
\hline Yes & $126 / 519$ & 24.3 & $5 / 135$ & 3.7 \\
\hline
\end{tabular}

$* p<0.05$ by Chi-Square test.

Table 4. Correlation coefficient of uric acid and independent variable by gender

\begin{tabular}{lcc}
\hline \multirow{2}{*}{ Independent Variable } & \multicolumn{2}{c}{ Uric acid } \\
\cline { 2 - 3 } & $0.09^{*}$ & Women \\
\hline AST (unit/liter) & $0.18^{\star}$ & $0.17^{\star}$ \\
ALT (unit/liter) & $0.14^{\star}$ & $0.18^{*}$ \\
GGT (unit/liter) & $-0.11^{\star}$ & $0.18^{\star}$ \\
HDL-cholesterol (mg/dL) & $0.14^{*}$ & -0.04 \\
Total-cholesterol (mg/dL) & $0.20^{*}$ & $0.17^{\star}$ \\
Triglyceride (mg/dL) & -0.05 & $0.19^{*}$ \\
Glucose (mg/dL) & $-0.15^{\star}$ & 0.05 \\
HDL-C/Total-C & $-0.19^{*}$ & $-0.15^{\star}$ \\
HDL-C/Triglyceride & $-0.14^{*}$ \\
\hline
\end{tabular}

AST: aspartate aminotransferase, ALT: alanine aminotransferase, GGT: gammaglutamyl transpeptidase, HDL-C: HDL-cholesterol, Total-C: total cholesterol. ${ }^{*} \mathrm{p}<0.05$.
$80.8 \%$, 여자가 $19.2 \%$ 를 차지하였다. 그리고 남자 중 30 대가 476 명으로 전체의 $31.4 \%$ 를 차지하였고, 여자는 40 대가 185 명으로 전체의 $51.2 \%$ 를 차지하였다. 음주 여부는 대상자 중 남자는 $73.5 \%$, 여자는 $40.4 \%$ 가 음 주를 하고 있다고 대답하였다. 여자에 비해 남자가 1.8 배 이상 많이 음 주를 하고 있었다. 그리고 중등도 이상의 운동 여부는 대상자 중 남자 는 $15.9 \%$, 여자는 $17.5 \%$ 로 남녀에서 비슷한 비율을 보였다(Table 2).

\section{3. 독립변수에 따른 고요산혈증 유병률}

연구대상자 중 연령에 따른 고요산혈증의 유병률은 남자는 20 대에 서 $30.8 \%$ 로 여자도 20 대에서 $4.8 \%$ 로 높았다. 음주 여부에 따른 고요 산혈증 유병률은 남자에서 음주를 하는 사람은 $23.8 \%$, 음주를 하지 않는 사람은 $20.4 \%$ 로 음주를 하는 남자가 높았고, 여자에서 음주를 하는 사람은 $2.1 \%$, 음주를 하지 않는 사람은 $2.8 \%$ 로 음주를 하는 사 람이 낮았다.

운동 여부에 따른 고요산혈증 유병률은 남자에서 운동강도가 중 등도 이상으로 운동하는 사람이 $23.7 \%$, 운동을 하지 않는 사람이 $22.8 \%$ 이고, 여자에서 운동하는 사람이 $3.2 \%$, 운동하지 않는 사람이 $2.3 \%$ 였다. 운동 여부는 운동강도에 관계없이 운동을 하지 않는 사람 보다 운동하는사람이 높은 유병률을 보였다(Table 3).

\section{Uric acid와 독립변수와 상관관계}

남녀 모두에서 Uric acid와 AST, ALT, GGT는 유의한 양의 상관관계를 $(\mathrm{p}<0.05)$ 를 보였고, HDL-cholesterol, HDL-C/Total-C, HDL/Triglyceride는 남녀 모두에서 유의한 음의 상관관계를 보였다 $(\mathrm{p}<0.05)$. Totalcholesterol과 triglyceride는 uric acid 농도가 높을수록 유의하게 상관 관계도가 높았다 $(\mathrm{p}<0.05)$. Glucose는 유의한 경향을 나타내지 않았 다(Table 4).

Table 5. The result of multiple regression analysis by gender

\begin{tabular}{lcccccc}
\hline & \multicolumn{3}{c}{ Men } & & \multicolumn{2}{c}{ Women } \\
\cline { 2 - 3 } \cline { 5 - 6 } & \multicolumn{1}{c}{$\beta$} & $\mathrm{t}$ & & $\mathrm{B}$ & $\mathrm{t}$ \\
\hline Age (year) & -0.19 & $-7.34^{*}$ & & - & - \\
AST (unit/liter) & -0.05 & -1.32 & & 0.05 & 0.45 \\
ALT (unit/liter) & 0.11 & $3.03^{*}$ & & 0.07 & 0.59 \\
GGT (unit/liter) & 0.07 & $2.45^{*}$ & & 0.08 & 1.27 \\
HDL Cholesterol (mg/dL) & -0.06 & -1.07 & & - \\
Total Cholesterol (mg/dL) & 0.12 & $2.74^{*}$ & & 0.09 & 1.41 \\
Triglyceride (mg/dL) & 0.08 & $2.54^{*}$ & & 0.15 & $2.09^{*}$ \\
HDL-C/Total-C & 0.06 & 1.08 & & -0.04 & -0.51 \\
HDL-C/Triglyceride & -0.11 & $-2.60^{*}$ & & 0.03 & 0.36 \\
Adjusted R & \multicolumn{3}{c}{0.11} & & \multicolumn{3}{c}{0.06} \\
F value & \multicolumn{3}{c}{$20.7^{*}$} & & & \\
\hline
\end{tabular}

AST: aspartate aminotransferase, ALT: alanine aminotransferase, GGT: gammaglutamyl transpeptidase, HDL-C: HDL-cholesterol, Total-C: total cholesterol. ${ }^{*} \mathrm{p}<0.05$. 


\section{5. 다중회귀분석 결과}

연구 대상자들의 Uric acid에 미치는 영향인자들에 대한 다중회귀분 석결과 남자는 연령과 HDL-C/Triglyceride 가 유의한 음의 변수였고 $(\mathrm{p}<0.05)$, ALT, GGT, Total-cholesterol, triglyceride 는 유의한 양의 변수 였다 $(\mathrm{p}<0.05)$. 또한 여자는 triglyceride 만 유의한 양의 변수였다 $(\mathrm{p}<0.05)($ Table 5).

\section{고 찰}

본 연구에서는 고요산혈증에 관련된 위험 요인들을 조사하여 질환 과 관련 요인을 제시하고, 물리치료 분야에서 통풍 치료를 위한 정보 를 마련하고자 생활습관 지표들과 함께 혈청지질, 간기능 지표, 고요 산혈증과의 관련성을 평가하였다.

본 연구결과, 남녀 연구 대상자 모두에서 uric acid와 간기능을 나타 내는 AST, ALT, GGT에서 유의한 양의 상관관계를 보였으며, 이는 음 주를 하는 사람들에서 고요산혈증의 유병률이 높은 결과와 일치하 였고 uric acid 농도가 높을수록 간기능이 저하된다는 의미로 생각된 다. 또한 HDL-cholesterol, HDL-C/Total-C, HDL-Triglyceride 는 남녀 모두에서 유의한 음의 상관관계를 보였으며, 이는 uric acid 가 높을수 록 인체에 좋은 작용을 하는 $\mathrm{HDL}-\mathrm{C}$ 가 낮거나 중성지방 혹은 총 콜 레스테롤이 높다는 것을 의미한다. Total-cholesterol과 triglyceride는 uric acid 농도와 유의하게 높은 상관관계를 보여 uric acid의 농도가 높을수록 총 콜레스테롤과 중성지방이 증가한다는 의미로 생각할 수 있다.

통풍의 유병률에 관한 결과에서는 남자 유병률이 $22.9 \%$ 를 보였고 여자의 경우는 연구대상 361 명 중 $2.5 \%$ 에서만 고요산혈증을 나타내 어 남자들과는 다른 양상을 보였다. 우리나라의 최근 조사된 연구 자 료인 국민건강보험공단의 통계에 따르면, 우리나라 국민들의 통풍 유 병률이 2001년에는 $0.17 \%, 2008$ 년에는 $0.4 \%$ 로 상당히 증가하여 통풍 환자들이 많이 늘어나고 있다고 보고하였다.22 미국에서 조사된 연구 를 살펴보면, ${ }^{21} 1990$ 년 미국인 전체 통풍 유병률은 $0.29 \%$ 였고 75 세 이 상의 노인에게서는 $0.21 \%$ 였으나, 9년 후인 1999년에는 미국인 전체 통 풍 유병률이 $0.52 \%, 75$ 세 이상의 노인에게서는 $0.41 \%$ 로 약 2 배 정도 증 가하였다. 그리고 2007과 2008년 사이에 진행된 미국의 The third national health and nutrition examination survey (NHANESIII)에서는 미 국의 통풍 유병률이 $3.9 \%$ 이고, 고요산혈증의 유병률은 $21.5 \%$ 로 나타 났다. ${ }^{2}$ 이와같이 미국뿐만 아니라 우리나라에서도 통풍과 고요산혈 증 환자가 증가하는 이유로는 우선 인류의 수명이 점차 증가하고 있 음에 따라 통풍에 걸릴 가능성이 높아졌고 경제상황이 좋아지면서 단백질과 지방을 많이 함유한 음식과 알코올의 섭취가 증가하였다. 이에 따라 비만 인구 및 고혈압 환자들이 증가하면서 고요산혈증을
유발하는 이뇨제의 사용이 증가하고 신장질환의 빈도가 증가하기 때문으로 추정되고 있다. ${ }^{23}$ 통풍과 대사증후군과의 관계를 보면 미국 에서 시행된 NHANESIII 조사에서 1994-1998년 사이 대사증후군이 동반된 비율은 통풍이 있던 환자에서 $62.8 \%$ 인 데 비해 통풍이 없었 던 환자에서는 $25.4 \%$ 였다. ${ }^{24}$ 통풍환자의 복부 비만의 위험은 2.55 배, 고중성지방혈증의 위험은 1.9 배, 콜레스테롤혈증의 위험은 1.6 배, 고 혈압의 위험은 2.63 배, 고혈당의 위험은 2.14 배로 정상인에 대사증후 군의 모든 면이 유의하게 높게 나타났다. ${ }^{4}$ 또한 비만과 체지방 증가가 통풍의 위험인자이고 체중이 감소하면 통풍의 위험도도 감소한다고 하였다. ${ }^{25}$ 통풍으로 진단된 환자뿐만 아니라 고요산혈증만 있는 환자 도 대사증후군의 위험이 증가된다고 하였다. ${ }^{26}$ 통풍과 고요산혈증과 고혈압의 상관관계를 보면 증가된 요산 자체가 고혈압의 위험인자가 되며 혈청 요산이 증가되어 있는 고혈압 환자에게 요산을 감소시키 면 혈압이 낮아진다고 하였다.27-30 통풍과 고지혈증과의 관계를 보고 한 연구한 연구는 통풍환자의 75-85\%에서 고중성지방혈증이 동반되 었다고 하였으며, 고중성지방환자의 $80 \%$ 이상에서 고요산혈증이 발 견된다고도 보고하였다. ${ }^{31}$ 미국 뉴욕의 보훈병원에서 통풍환자들을 대상으로 동반질환에 관한 연구결과에서 고혈압이 $88.7 \%$ 로 가장 많 았으며, 고지혈증이 $62.6 \%$, 만성 신장질환이 $47.1 \%$, 관상동맥질환이 $37.4 \%$, 당뇨병이 $28.9 \%$ 로 나타났고 동반질환이 없는 경우는 $2.4 \%$ 였 다. ${ }^{32}$

우리나라에서 조사한 통풍과 대사증후군의 관련성에 관한 연구 에서는 통풍환자의 $42.2 \%$ 에서 대사증후군을 동반하여 $50 \%$ 에서 고 혈압, $11 \%$ 에서 당뇨병을 동반한다고 하였다. ${ }^{33}$ 통풍은 대사성 증후로 인한 근골격계 장애를 유발하는 질환으로 통증을 비롯한 다양한 관 절염성 증상을 나타낸다. 통풍의 근원적 치료는 요산의 감소가 결정 적인 요소이지만, 관절 주변에 염증을 유발하는 관절 질환으로 통증, 부종, 연부조직 구축 등을 동반한다. 따라서 통풍으로 인한 이차적인 관절 주변 연부 조직의 손상을 미연에 치료하고 예방하는 치료가 필 요하다. 또한 현대인들의 생활 및 식습관의 변화와 수명 연장으로 인 해 매년 통풍 환자가 증가하는 추세에 있어 물리치료 분야에서 통풍 에 관한 관심과 치료적 지침에 대한 과학적 근거에 입각한 문헌의 제 시가 필요할 때라 생각된다. 따라서 본 연구에서는 우리나라 성인에 서 유발될 수 있는 통풍의 유병률과 유발 인자에 대해 알아보고자 하 였다. 이 연구에서 몇 가지 제한점으로는 여자 대상자 수가 남자에 비 해 너무 부족하였고 연구 대상 지역이 전국을 대표하기보다는 특정 지역을 한정하여 전국적인 대표성이 부족하였다. 또한, 지속적인 추 적관찰을 통해 질환율의 변화 양상을 조사하지 못하였다. 향후 연구 에서는 전국 단위의 샘플링과 지속적 추적 관찰이 가능한 연구가 필 요할 것으로 사료된다. 


\section{Acknowledgements}

이 연구는 2014학년도 영남이공대학교 연구조성비 지원에 의한 것임.

\section{참고문헌}

1. Choi HK, Mount DB, Reginato AM. Pathogenesis of gout. Ann Intern Med. 2010;143:499-516.

2. Kuo CF, Grainge MJ, Mallen C et al. Rising burden of gout in the UK but continuing suboptimal management: a national population study. Annals of the rheumatic disease. 2015;74(4):661-7.

3. Robinson PC, Taylor WJ, Meriman TR. Systematic review of the prevalence of gout and hyperuricemia in Australia. Internal Medicine journal. 2012;42(9):997-1007.

4. Winnard D, Wright C, Taylor WJ et al. National prevalence of gout derivative from administer health data Aotearoa NewZealand. Rheumatology (Oxford, England). 2012;51:901-9.

5. Kuo CF, Grainge MJ, Zhang W et al. Global epidemiology of gout. Prevalence, incidence and risk factors. Nature reviews rheumatology. 2015.

6. Abbott RD, Brand FN, Kannel WB et al. Gout and coronary heart disease: the Framingham study. J Clin Epidemiol. 1988;41(3):237-42.

7. Chen SY, Chen CL, Shen ML. Severity of gouty arthritis is associated with Q-wave myocardial infarction: a large-scale, cross-sectional study. Clin Rheumatol. 2007;26(3):308-13.

8. Full LE, Ruisanchez C, Monaco C. The inextricable link between atherosclerosis and prototypical inflammatory diseases rheumatoid arthritis and systemic lupus erythematosus. Arthritis Res Ther. 2009;11(2):217.

9. Krishnan E, Svendsen K, Neaton JD et al. Long-term cardiovascular mortality among middle-aged men with gout. Arch Intern Med. 2008; 168(10):1104-10.

10. Choi HK, Curhan G. Independent impact of gout on mortality and risk for coronary heart disease. Circulation. 2007;116(8):894-900.

11. Ishizaka N, Ishizaka Y, Toda E et al. Association between serum uric acid, metabolic syndrome, and carotid atherosclerosis in Japanese individuals. Arterioscler Thromb Vasc Biol. 2005;25(5): 1038-44.

11. Ito $\mathrm{H}$, Abe M, Mifune M et al. Hyperuricemia is independently associated with coronary heart disease and renal dysfunction in patients with type 2 diabetes mellitus. PLoS One. 2011;6(11):e27817.

12. Zhu Y, Pandya BJ, Choi MK. Prevalence and hyperuricemia in the US general population: the national health and nutrition examination survey 2007-2008. Arthritis and rheumatism. 2011;63(10):3136-41.

13. Rathmann W, Funkhouser E, Dyer AR et al. Relations of hyperuricemia with the various components of the insulin resistance syndrome in young black and white adults: the CARDIA study. Coronary artery risk development in young adults. Ann Epidemiol. 1998;8(4):250-61.

14. Choi HK, Ford ES, Li C et al. Prevalence of the metabolic syndrome in patients with gout: the third national health and nutrition examination survey. Arthritis Rheum. 2007;57(1):109-15.

15. Rho YH, Choi SJ, Lee YH et al. The prevalence of metabolic syndrome in patients with gout: a multicenter study. J Korean Med Sci. 2005;
20(6):1029-33

16. Feig DI, Kang DH, Johnson RJ. Uric acid and cardiovascular risk. N Engl J Med. 2008;359:1811-21.

17. Choi HK. A prescription for lifestyle change in patients with hyperuricemia and gout. Curr Opin Rheumatol. 2010;22(2):165-72.

18. Bae J, Chun BY, Park PS et al. Higher consumption of sugar-sweetened soft drinks increases the risk of hyperuricemia in Korean population: the Korean multi-rural communities cohort study. Semin Arthritis Rheum. 2014;43(5):654-61.

19. Park EH, Park JH, Song JS et al. Two-year follow-up study of the relationship between the changes of serum homocysteine and those of serum uric acid levels. Lipid Profiles and Renal Function in Gout Patients Journal of Rheumatic Diseases. 2016;23(1):30-6.

20. Fang J, Alderman MH. Serum uric acid and cardiovascular mortality: the NHANES I epidemiologic follow-up study, 1971-1992. National Health and Nutrition Examination Survey. JAMA. 2000;283(18):240410.

21. Wallace KL, Riedel AA, Joseph-Ridge $\mathrm{N}$ et al. Increasing prevalence of gout and hyperuricemia over 10 years among older adults in a managed care population. J Rheumatol. 2004;31(8):1582-7.

22. Lee CH, Sung NY. The prevalence and features of Korean gout patients using the national health insurance corporation database. J Rheum Dis. 2011;18:94-100.

23. Song JS, Rising Gout. Life threatening public enemy. J Korean Rheum Assoc. 2011;18:234-41.

24. Lee SJ, Hirsch JD, Terkeltaub R et al. Perceptions of disease and healthrelated quality of life among patients with gout. Rheumatology (Oxford). 2009;48(11):582-6.

25. Choi HK, Atkinson K, Karlson EW et al. Obesity, weight change, hypertension, diuretic use, and risk of gout in men: the health professionals follow-up study. Arch Intern Med. 2005;165(7):742-8.

26. Puig JG, Martinez MA, Mora M et al. Serum urate, meabolic syndromk factors: a population-based study. Nucl-eosides Nucleotides Nucleic Acids. 2008;47(6):1567-70.

27. Mazzali M, Kanellis J, Han L et al. Hyperuricemia induces a primary renal arteriol-opathy in rats by a blood pressure-independent mechanism. Am J Physiol Renal Physiol. 2002;282(6):F991-7.

28. Khosla UM, Zharikov S, Finch JL et al. Hyperuricemia induces endothelial dysfunction. Kidney Int. 2005;67():1739-42.

29. Mazzali M, Hughes J, Kim YG et al. Elvated uric acid increases blood pres-sure in the rat by a novel crystal-independent mechanism. Hypertension. 2001;38():1101-6.

30. Sanchez-Lozada LG, Tapia E, Santamaria J et al. Mild hyper-uricemia induces vasoconstriction and maintains glomer-ular hypertension in nomal and remnant rats. Kidney Int. 2005;67(5):237-47.

31. Emmerson B. Hyperlipidaemia in hyperuricaemia and gout. Ann Rheum Dis. 1998;57(9):509-10.

32. Keenan RT, O'Brien WR, Lee KH et al. Prevalence of contraindications and prescription of pharmacologic therapies for gout. Am J Med. 2011; 124(2):155-63.

33. Rho YH, Choi SJ, Lee YH et al. Prevalence of the metabolic syndrome in patients with gout. J Korean Rheum Assoc. 2004;11(6):349-57. 